\title{
EDUCAÇÃO SEXUAL E LEGITIMIDADE DO PROFESSOR DE ENSINO BÁSICO: UM ESTUDO COMPARATIVO ENTRE BRASIL E PORTUGAL
}

\author{
Rafaela Cordeiro Gama \\ Doutoranda em Estudos da Criança, CIEC \\ Instituto de Educação da Universidade do Minho \\ rah.rafaela@gmail.com \\ Zélia Caçador Anastácio \\ CIEC, Instituto de Educação da Universidade do Minho \\ zeliaf@ie.uminho.pt
}

Fecha de Recepción: 2 Septiembre 2019

Fecha de Admisión: 25 Septiembre 2019

\section{RESUMO}

Sendo parte de uma investigação mais ampla de doutoramento, este trabalho tem como objetivo apresentar reflexões iniciais acerca da regulamentação da Educação Sexual (ES) e da legitimidade do professor de Anos Iniciais do Ensino Fundamental, no Brasil, e de 1. ${ }^{\circ}$ Ciclo do Ensino Básico (1.. CEB), em Portugal, para a sua abordagem junto das crianças, nomeadamente dos temas relacionados à sexualidade e género. Em Portugal, a Educação Sexual é obrigatória a partir do 1. ${ }^{\circ}$ CEB desde a aprovação da Lei n..- 60/2009 de 6 de agosto. Já no Brasil, com a aprovação em 2018 da Base Nacional Comum Curricular, os termos Orientação Sexual e género foram suprimidos. A supressão destes termos torna-se problemática no sentido em que invisibiliza as discussões sobre temas relacionados à sexualidade e género, como conhecimento do corpo e respeito à diversidade, que também estão contemplados na BNCC. Sendo um estudo comparativo seguindo uma metodologia qualitativa, nesta fase proceder-se-á a uma análise documental dos documentos orientadores da ES nos dois países. Neste artigo, abordar-se-á, especificamente, a fase de diagnóstico da pesquisa no que diz respeito aos primeiros resultados da análise documental das legislações e documentos oficiais em relação aos temas da investigação. Percebe-se que a obrigatoriedade da Educação Sexual em Portugal possibilitou um trabalho sistemático e específico no trato dos temas sexualidade e questões de género, com acompanhamento e avaliação do trabalho nas escolas. Já em relação à realidade brasileira os desafios são diferentes. Acredita-se também que não explicitar 0 trabalho em Educação Sexual nos Anos Iniciais do Ensino Fundamental fere 0 direito de acesso à informação e construção de conhecimento acerca do tema.

Palavras-chave: sexualidade; género; professores; primeiro ciclo do ensino básico; anos iniciais do ensino fundamental.

\section{ABSTRACT}

Sexual education and legitimity of the basic teaching teacher: a comparative study between Brazil and Portugal. Being part of a wider PhD research, this paper aims to present initial reflections about the 


\section{EDUCAÇÃO SEXUAL E LEGITIMIDADE dO PROFESSOR DE ENSINO BÁSICO: UM ESTUdO COMPARATIVO ENTRE BRASIL E PORTUGAL}

regulation of Sex Education (ES) and the legitimacy of the teacher in Early Years of Elementary School, in Brazil, and 1st Cycle of Basic Education (1st CEB), in Portugal, for their approach to children, particularly on issues related to sexuality and gender. In Portugal, Sex Education is compulsory from the 1st CEB since the approval of Law No. 60/2009 of August 6. Otherwise, in Brazil, with the approval in 2018 of the Common National Curriculum Base (Base Nacional Comum Curricular - BNCC), the terms Sexual Orientation and gender were suppressed. The suppression of these terms becomes problematic since it makes invisible discussions on issues related to sexuality and gender, such as body awareness and respect for diversity, which are also covered by the BNCC. Being a comparative study based on a qualitative methodology, at this stage will be made a documentary analysis of the Sexual Education guiding documents in both countries. This article will specifically address the diagnosis step of the research regarding the first results of documentary analysis of legislation and official documents in relation to the topics of this research. The compulsory sexuality education in Portugal made possible a systematic and specific work in dealing with sexuality and gender issues, with monitoring and evaluation of work in schools. In relation to the Brazilian reality, the challenges are different. It is also believed that not explaining the work in Sexuality Education in the Early Years of Elementary School hurts the right of access to information and the knowledge building on the subject.

Keywords: sexuality; gender; teachers; first cycle of basic education; early years of elementary school.

\section{INTRODUÇÃO}

0 presente artigo tem como objetivo apresentar as reflexões iniciais acerca da regulamentação da Educação Sexual (ES) e da legitimidade do professor de Anos Iniciais do Ensino Fundamental, no Brasil, e de 1. ${ }^{\circ}$ Ciclo do Ensino Básico (1.드), em Portugal, para a sua abordagem junto das crianças, nomeadamente dos temas relacionados a sexualidade e género.

É um facto que os casos de violência e discriminação relacionados a género e sexualidade, no Brasil e no mundo, têm tido grande repercussão, principalmente pelo nível de crueldade observado, como, por exemplo, no caso de assassinato da travesti Dandara dos Santos, no Ceará em 2017 (Cinco dos acusados, 2018).

0 Brasil foi considerado em 2016, segundo Ayer \& Bottrel (2017), o país que mais mata travestis e transexuais no mundo. Entretanto, os autores destacam que os números de casos em que a violência é incitada por transfobia ainda são subnotificados pela falta de estatísticas oficiais.

Em junho de 2019 foi aprovada pelo Superior Tribunal Federal (STF) brasileiro a criminalização da discriminação homofóbica e transfóbica (Barifouse, 2019), sendo enquadrada na Lei de Racismo, enquanto os projetos de lei que tratam sobre o tema e que tramitam no legislativo não fossem aprovados.

Já em relação à violência contra a mulher é uma questão antiga, mas a preocupação em superar essa situação é recente. Por exemplo, no Brasil a Lei 11.340, conhecida como lei Maria da Penha, que destaca e incrementa 0 rigor das punições aos que cometem esse tipo de crime, foi sancionada apenas em 2006. E só em 2015 foi aprovada a Lei 13.104, a lei do Feminicídio, que tipifica como crime hediondo os homicídios de mulheres por razões de sexo.

A violência contra a mulher não é uma realidade apenas no Brasil, e sim uma realidade mundial. No relatório "As Estimativas Globais e Regionais da Violência contra as Mulheres: a prevalência dos efeitos da violência sexual exercida por parceiro fixo e parceiro eventual e a saúde" divulgado no ano de 2013, as Nações Unidas destacaram que mais de um terço das mulheres em todo o mundo são afetadas pela violência física ou sexual e na maioria das vezes 0 agressor é o próprio parceiro. 0 relatório também destacou que ainda existe um medo de estigmas por parte de muitas mulheres que as impedem de denunciar a violência sexual (Centro Regional de Informação das Nações Unidas, 2013).

Em Portugal essa realidade não é diferente. Segundo o Observatório das Mulheres Assassinadas, da União de Mulheres Alternativa e Resposta (UMAR), foram registados 454 assassinatos de mulheres no país desde 2004, assinalando também que em $83 \%$ dos crimes o homicida tinha ou teve uma relação de intimidade com a vítima (Lusa, 2016). 


\section{PSICOLOGÍA, INFANCIA Y EDUCACIÓN}

Com todas essas notícias alarmantes sobre 0 aumento de casos notificados acerca da violência de género e sexual, emerge a discussão acerca da realidade do trabalho sobre questões de género e sexualidade em meio escolar.

Realizando uma busca rápida na plataforma do Google sobre notícias acerca das questões de género e sexualidade, surgem milhares de notícias brasileiras sobre diversos vieses, principalmente no debate na área da educação (Almeida, Ghisi \& Rodrigues, 2019; Cecílio, 2019; Toledo, 2019).

Mais recentemente, 0 debate político relacionado a essas temáticas se intensificou no Brasil com as eleições de 2018. E também com a crescente disputa de diferentes bancadas parlamentares no que diz respeito às políticas públicas sobre 0 trabalho de questões de sexualidade e género na educação brasileira (Carta Capital, 2019; Fonseca, 2019; Moura, 2019).

Nesse sentido, diversos projetos de lei (PL) foram criados no Brasil, tanto nos âmbitos municipais e estaduais quanto na esfera federal, com o objetivo de limitar e até proibir 0 debate e a abordagem de temas relacionados às questões de sexualidade e género no currículo das escolas brasileiras de educação básica, principalmente as públicas.

Dessa forma, são crescentes os estudos e as pesquisas académicas em relação às temáticas de sexualidade e género. Além disso, no debate brasileiro sobre a luta social por direitos desde a aprovação da Constituição de 1988, também se observa um crescente espaço de discussão e, consequentemente, de disputa sobre as temáticas (Vianna, Carvalho, Schilling \& Moreira, 2011).

Para esse artigo, deseja-se contextualizar o que se entende por sexualidade e género no contexto da investigação que está sendo realizada no âmbito do doutoramento.

0 conceito de sexualidade está em constante transformação, impulsionada pelas contradições e pela diversidade de ideias existentes na construção do conhecimento. Assim, o que se entende por sexualidade muda ao longo dos séculos, passando por diversas transformações ao longo da história. Em 2006, a World Health Organization (WHO) definiu sexualidade do seguinte modo:

Sexuality is a central aspect of being human throughout life and encompasses sex, gender identities and roles, sexual orientation, eroticism, pleasure, intimacy and reproduction. Sexuality is experienced and expressed in thoughts, fantasies, desires, beliefs, attitudes, values, behaviours, practices, roles and relationships. While sexuality can include all of these dimensions, not all of them are always experienced or expressed. Sexuality is influenced by the interaction of biological, psychological, social, economic, political, cultural, ethical, legal, historical, religious and spiritual factors. (WH0, 2006, p. 5)

0 conceito de sexualidade passou a envolver não apenas aspectos biológicos, mas também sociais, afetivos, psicológicos, entre outros. Nesse sentido, no âmbito escolar, a abordagem biológico-higienista ainda presente nas práticas dos educadores no ensino formal é limitante e não alcança outras problemáticas observadas nas relações sociais. Nesse sentido, ao considerar outros aspectos da sexualidade, diversas e importantes discussões surgem, nomeadamente, sobre a violência de género, a equidade de género, os estereótipos de género, a violência sexual, entre outros. Assim, torna-se necessário trazer essas discussões para o cotidiano escolar (Furlani, 2011).

Nas mais recentes orientações internacionais para a educação para a sexualidade (UNESCO, 2018), entre os oito conceitos chave a trabalhar, o terceiro intitula-se "Entendimento de género", legitimando claramente a sua abordagem com crianças a partir dos 5 anos de idade, começando pela distinção entre sexo biológico e género. 0 termo género surge com as feministas anglo-saxãs, que tinham o objetivo de enfatizar por meio da linguagem o caráter fundamentalmente social das distinções baseadas no sexo biológico (Scott, 1995; Louro, 2014). Assim, o conceito de género está relacionado à forma como somos socializados, ou seja, como nossas expectativas, nossos comportamentos e nossas atitudes são constituídos com base no que a cultura atribui como adequado e oportuno ao sexo feminino e ao sexo masculino. 


\section{EDUCAÇÃO SEXUAL E LEGITIMIDADE DO PROFESSOR DE ENSINO BÁSICO: UM ESTUDO COMPARATIVO ENTRE BRASIL E PORTUGAL}

Nesse sentido, as questões de género estão presentes na vida de uma pessoa desde antes de nascer. Uma das principais perguntas que são feitas às pessoas que estão à espera de uma criança é se é menina ou menino. A partir daí, na maioria dos casos, todos os objetos da criança e as expectativas de vida sobre a mesma são condicionados a essa questão. E isso continua ao longo de toda a vida da pessoa, em diversos contextos da sociedade. Além disso, o conceito de género é assumido como uma categoria analítica do processo histórico, pretendendo "se referir ao modo como as características sexuais são compreendidas e representadas" (Louro, 2014, p. 26), denunciando as desigualdades que surgem baseadas no género.

Estas discussões sociais são transpostas para a escola, que tem a missão de educar por meio dos seus agentes que são os professores. Todavia, no contexto destas problemáticas que se constituem em questões socialmente vivas (Simmoneaux, 2003), os professores não Ihes podem ficar alheios, do mesmo modo que nem sempre de sentem habilitados para as abordar. Importa por isso, analisar a legitimidade que é conferida ao professor dos anos iniciais para abordar estas questões de sexualidade e género.

\section{OBJETIVOS DA INVESTIGAÇÃO}

Este trabalho faz parte de uma investigação mais ampla de doutoramento, a qual está em andamento e objetiva analisar se os professores dos Anos Iniciais do Ensino Fundamental, no Brasil, e os professores de Primeiro Ciclo do Ensino Básico (1ํ CEB), em Portugal, se reconhecem como profissionais legitimados a tratar de questões de sexualidade e género no âmbito da educação para a sexualidade.

\section{PARTICIPANTES}

Os participantes da investigação serão professoras/es dos Anos Iniciais do Ensino Fundamental no Brasil e professoras/es do 1.․ㅡ CEB de Portugal. A escolha dos participantes desse nível de ensino se justifica por conta da motivação profissional de discutir sobre a importância da abordagem de questões de género e sexualidade com crianças dessa faixa etária. Além disso, em Portugal a Educação Sexual é obrigatória a partir do primeiro ano do ensino básico, o que atende às normativas internacionais sobre Educação para a sexualidade.

\section{METODOLOGIA E INSTRUMENTOS UTILIZADOS}

Para esta investigação de doutoramento, selecionou-se uma metodologia mista, pesquisa-ação. Quanto ao tipo trata-se, assim, de um estudo comparativo, principalmente na fase de diagnóstico, momento de investigação nos dois países.

Dadas as diferentes fases da pesquisa-ação, desde o diagnóstico até à avaliação, aplicar-se-ão diferentes técnicas e instrumentos de recolha de dados, assumindo-se ser de caráter predominantemente qualitativo, embora também se proceda a algumas técnicas quantitativas.

Neste artigo, abordar-se-á, especificamente, a fase de diagnóstico da pesquisa no que diz respeito aos primeiros resultados da análise documental das legislações, documentos oficiais e políticas públicas em relação aos temas da investigação.

Nesse sentido, buscou-se comparar como os temas sexualidade e género aparecem e são abordados nos currículos escolares dos dois países, referente principalmente ao Anos Iniciais do Ensino Fundamental no Brasil e $01^{\circ}$ CEB em Portugal. Além disso, compara-se esses documentos com as diretrizes internacionais da Organização Mundial da Saúde (OMS) e da UNESCO no que se refere ao trabalho desses temas em meio escolar e na faixa etária correspondente a esses níveis de ensino.

\section{RESULTADOS ALCANÇADOS}

Neste artigo apresenta-se os resultados parciais relativos à fase de diagnóstico, nomeadamente ao levantamento das legislações, documentos oficiais e políticas públicas dos dois países em relação aos temas de sexualidade e questões de género. Inicia-se assim, com a exposição de normativas internacionais sobre Educação para a Sexualidade (ES) nos documentos internacionais. 


\section{Documentos Orientadores da ES a nível Internacional}

Nas diretrizes da Organização Mundial de Saúde (2010), no documento Standards for Sexuality Education in Europe - a framework for policy makers, educational and health authorities and specialists, existem os seguintes temas gerais: corpo humano e desenvolvimento; reprodução e fertilidade; sexualidade; emoções; relacionamentos; sexualidade, saúde e bem-estar; sexualidade e direitos; valores e normas sociais e culturais relacionados à sexualidade.

Dentro desses temas gerais, referente à faixa etária abordada na investigação, são estabelecidos temas específicos em relação às questões de sexualidade e género, como relações em geral; diversidade de género e direito a expressão; respeito à diversidade sexual e de género; autoimagem corporal positiva; conhecimento do corpo humano; respeito ao próprio corpo e das outras pessoas, entre outras questões.

Já no documento International technical guidance on sexuality education: An evidence informed approach for schools, teachers and health educators, publicado em 2009 pela UNESCO, encontram-se alguns objetivos de aprendizagem para o meio escolar. A partir de conceitos chaves, foram estabelecidos tópicos específicos e assim desenvolvidos os objetivos de aprendizagem. A abordagem dos temas é norteada pela questão da faixa etária, sendo possível trabalhar questões específicas com cada uma delas. Nesse sentido, a partir dos cincos anos temas relacionados à sexualidade e questões de género são abordados.

Em relação à faixa etária correspondente aos níveis de ensino abordados na investigação, o documento especifica a abordagem de temas como diversidade de estruturas familiares; papéis de género; equidade e desigualdade entre os géneros; diversidade sexual; problematização de preconceitos, discriminação e estigmas relacionados à sexualidade e género; sexualidade, género e médias, entre outros temas.

\section{Documentos Orientadores da ES em Portugal}

Em Portugal, a Educação Sexual é uma temática obrigatória nas escolas de ensino básico e de ensino secundário no âmbito da educação para a saúde, desde a aprovação da Lei n.․ㅜ 60/2009. Nesta lei apresentam-se todas as características legais que fundamentam a obrigatoriedade do tema e como deve ser organizado no currículo e nos projetos educativos da escola.

A educação sexual em Portugal tem como finalidade, segundo a Lei n.. $60 / 2009$ (p. 5097), o seguinte:

a) A valorização da sexualidade e afectividade entre as pessoas no desenvolvimento individual, respeitando o pluralismo das conceções existentes na sociedade portuguesa;

b) 0 desenvolvimento de competências nos jovens que permitam escolhas informadas e seguras no campo da sexualidade;

c) A melhoria dos relacionamentos afectivo-sexuais dos jovens;

d) A redução de consequências negativas dos comportamentos sexuais de risco, tais como a gravidez não desejada e as infecções sexualmente transmissíveis;

e) A capacidade de protecção face a todas as formas de exploração e de abuso sexuais;

f) 0 respeito pela diferença entre as pessoas e pelas diferentes orientações sexuais;

g) A valorização de uma sexualidade responsável e informada;

h) A promoção da igualdade entre os sexos;

i) 0 reconhecimento da importância de participação no processo educativo de encarregados de educação, alunos, professores e técnicos de saúde;

j) A compreensão científica do funcionamento dos mecanismos biológicos reprodutivos;

l) A eliminação de comportamentos baseados na discriminação sexual ou na violência em função do sexo ou orientação sexual (Portugal, 2009).

A lei também estabelece uma carga horária mínima para cada nível de ensino que deve ser distribuída de forma equilibrada durante 0 ano letivo. Além disso, destaca que cada agrupamento de escolas e escolas não agru- 
padas devem ter uma equipa interdisciplinar de educação para a saúde e educação sexual com um professorcoordenador, e estabelece as responsabilidades dessa equipa e dos seus membros.

Quanto a avaliação, o Ministério da Educação deve acompanhar, supervisionar e coordenar o decorrer do trabalho na Educação Sexual e também deve preparar relatórios desse percurso preparados a partir do resultado de questionários aplicados nas escolas. (Portugal, 2009).

No documento Referencial de Educação para a Saúde do Ministério da Educação, de 2017, encontra-se 0 tema Afetos e Educação para a Sexualidade, o qual é subdividido em 6 subtemas: 1) identidade e género; 2) relações afetivas; 3) valores; 4) desenvolvimento da sexualidade; 5) maternidade e paternidade; 6) direitos sexuais e reprodutivos. Em cada subtema existem diferentes objetivos e habilidades acerca do que deve ser abordado e desenvolvido com as crianças.

No Quadro 1 pode-se observar esses objetivos e conteúdos referentes ao Primeiro Ciclo do Ensino Básico (1. - CEB), o qual corresponde aos Anos Iniciais do Ensino Fundamental no Brasil. Escolheu-se os subtemas $1 \mathrm{e}$ 4, por serem mais próximos dos temas desta pesquisa, além de serem trabalhados no nível de ensino pesquisado.

Quadro 1: Objetivos e habilidades dos subtemas da Educação para a sexualidade, referentes ao 1.․ㅡㄹ.

\begin{tabular}{|c|c|c|}
\hline Subtema & Objetivos & Habilidades \\
\hline \multirow[t]{2}{*}{$\begin{array}{l}\text { Identidade } \\
\text { Género }\end{array}$} & $\begin{array}{l}\text { Desenvolver } \\
\text { consciência de ser uma } \\
\text { pessoa única no que } \\
\text { respeita à sexualidade, à } \\
\text { identidade, à expressão } \\
\text { de género e à orientação } \\
\text { sexual }\end{array}$ & $\begin{array}{l}\text { Tomar consciência da diversidade das } \\
\text { expressões e identidades de género. } \\
\text { Compreender e respeitar a diversidade } \\
\text { na sexualidade (32) e na orientação } \\
\text { sexual. }\end{array}$ \\
\hline & $\begin{array}{l}\text { Desenvolver uma atitude } \\
\text { positiva no que respeita à } \\
\text { igualdade de género }\end{array}$ & $\begin{array}{l}\text { Analisar criticamente os diferentes } \\
\text { papéis socioculturais em função do } \\
\text { sexo. } \\
\text { Discutir o significado da promoção da } \\
\text { igualdade de direitos e oportunidades } \\
\text { entre homens e mulheres. }\end{array}$ \\
\hline \multirow[t]{2}{*}{$\begin{array}{l}\text { Desenvolvimento } \\
\text { da sexualidade }\end{array}$} & $\begin{array}{l}\text { Ser capaz de aceitar e } \\
\text { integrar as mudanças } \\
\text { físicas e emocionais } \\
\text { associadas à sexualidade, } \\
\text { ao longo da vida }\end{array}$ & $\begin{array}{l}\text { Identificar mudanças físicas } \\
\text { emocionais ao longo da vida. } \\
\text { Identificar a existência de um corpo } \\
\text { sexuado e as diversas formas de } \\
\text { identificação com o mesmo. } \\
\text { Valorizar a diversidade dos corpos. } \\
\text { Apreciar criticamente as mensagens } \\
\text { veiculadas pela comunicação social e } \\
\text { os padrões estéticos. } \\
\text { Desenvolver uma imagem corporal } \\
\text { positiva e respeito pelos outros. } \\
\text { Reconhecer a existência de regras } \\
\text { sociais sobre privacidade e intimidade. }\end{array}$ \\
\hline & $\begin{array}{l}\text { Ser responsável para } \\
\text { consigo e para com os } \\
\text { outros. }\end{array}$ & $\begin{array}{lcr}\text { Identificar a } & \text { sexualidade } & \text { como } \\
\text { componente } & \text { positiva } & \text { do } \\
\text { desenvolvimento } & \text { pessoal } & \text { e das } \\
\text { relações interpessoais. } & & \end{array}$ \\
\hline
\end{tabular}

Fonte: Portugal (2017) 
Entretanto, esse documento tem caráter não obrigatório, ou seja, se constitui como "uma ferramenta educativa flexível, de adoção voluntária, passível de ser utilizada e adaptada em função das opções e das realidades de cada contexto educativo, desde a educação pré-escolar ao ensino secundário, nas suas diferentes modalidades." (Portugal, 2017, p. 7). Dessa forma, o documento pode ser utilizado pelas escolas como um instrumento norteador do trabalho específico em Educação para a Sexualidade no país.

\section{Documentos Orientadores da ES no Brasil}

Já no Brasil, em 2018, foi aprovada a Base Nacional Comum Curricular (BNCC), se configurando como 0 principal documento norteador do currículo da escola de ensino regular. Esse documento tem caráter normativo e define as "aprendizagens essenciais" dos estudantes durante todas as etapas e modalidades da educação básica.

0 documento afirma também que a sua redação e conceção estão orientadas pelos "princípios éticos, políticos e estéticos que visam a formação humana integral e à construção de uma sociedade justa, democrática e inclusiva" (Brasil, 2018).

Em relação à questão dos temas abordados nesta pesquisa, a sexualidade ainda se configura como um tema transversal da educação formal. Entretanto, a abordagem da temática na BNCC, de forma explícita, se concentrou apenas no componente curricular de Ciências nos Anos Finais do Ensino Fundamental, mais precisamente no oitavo ano.

Entretanto, nas habilidades e conteúdos dos Anos Iniciais do Ensino Fundamental, o tema da sexualidade não está explícito, ou seja, não é citado o trabalho dessas temáticas com crianças desse nível de ensino. Já em relação à temática das questões de género essas não são contempladas no documento como um todo. 0 termo género só está elucidado no texto em relação à área de conhecimento de Linguagens, o que está relacionado com género textual.

Apesar disso, se considerarmos o conceito de sexualidade e de género contemporâneos, em determinadas áreas de conhecimento se destacam competências específicas as quais podem ser relacionadas com os conceitos. Ou seja, podemos entender que as temáticas podem ser contempladas nessas unidades temáticas pelo currículo escolar e pelo(a) professor(a).

Pode-se observar, no Quadro 2, as unidades temáticas dos Anos Iniciais do Ensino Fundamental, onde as temáticas de género e sexualidade podem ser trabalhadas:

Quadro 2: Unidades temáticas por Componente Curricular dos Anos Iniciais do Ensino Fundamental onde as questões de género e sexualidade podem ser trabalhadas

\begin{tabular}{|l|l|}
\hline Componente Curricular & \multicolumn{1}{|c|}{ Unidade temática } \\
\hline Ciências & Vida e Evolução \\
\hline Geografia & $\begin{array}{l}\text { O Sujeito e seu Lugar no Mundo; } \\
\text { Mundo do trabalho. }\end{array}$ \\
\hline História & $\begin{array}{l}\text { Mundo Pessoal: meu lugar no mundo; } \\
\text { Mundo Pessoal: eu, meu grupo social e meu tempo; } \\
\text { A comunidade e seus registros; } \\
\text { O trabalho e a sustentabilidade na comunidade; } \\
\text { As pessoas e os grupos que compõem a cidade e o } \\
\text { município; } \\
\text { O lugar em que vive; } \\
\text { A noção de espaço público e privado; } \\
\text { Povos e culturas: meu lugar no mundo e meu grupo social; } \\
\text { Registros da história: linguagens e culturas. }\end{array}$ \\
\hline
\end{tabular}

Fonte: Brasil (2018) 


\section{EDUCAÇÃO SEXUAL E LEGITIMIDADE dO PROFESSOR DE ENSINO BÁSICO: UM ESTUdO COMPARATIVO ENTRE BRASILE PORTUGAL}

Na BNCC aparece também a questão dos temas contemporâneos do currículo, onde é destacado que cabe aos sistemas e redes de ensino, e também às escolas, incorporar ao currículo e às propostas pedagógicas os temas que afetam a vida em sociedade. Esses temas propiciam a discussão de questões que tem relevância em escala local, regional e global, citando como exemplo de temas contemporâneos a Educação em Direitos Humanos (Decreto n..$-7.037 / 2009$, Parecer CNE/CP n.․ 8/2012 e Resolução CNE/CP n.ำ 1/2012); a questão da saúde, vida familiar e social e diversidade cultural (Parecer CNE/CEB n.. 11/2010 e Resolução CNE/CEB n.. 7/2010). Entretanto, a questão da sexualidade e do género não são destacados entres esses temas.

Percebe-se, portanto, que os documentos internacionais e o Referencial de Educação para a Saúde em Portugal, preconizam o trabalho em Educação para a sexualidade, onde as questões de género estão contempladas, desde a faixa etária que corresponde ao 1ํㅡㄹ. Já no Brasil, observa-se a omissão do trabalho no que se refere às questões de género na BNCC

\section{DISCUSSÃO}

Em 2016, a UNESCO no Brasil reafirmou a importância e a necessidade da legislação brasileira e dos planos de educação incorporarem perspetivas de educação em sexualidade e género, com o objetivo de diminuir a violência e a discriminação. Esse posicionamento surgiu por conta da onda de violência de género no país, com dados alarmantes sobre a situação de grupos em vulnerabilidade (Unesco, 2016).

A Educação para a sexualidade no Brasil é historicamente construída e constituída como um tema transversal no currículo da educação formal. Não existe a obrigatoriedade em relação ao tratamento de temas relacionados à sexualidade e nem às questões de género. Nesse sentido, o tema aparece oficialmente no currículo como um tema transversal na década de 1990 com os Parâmetros Curriculares Nacionais sobre Orientação Sexual (Brasil, 1997). Sobre esse documento, Silva, Brancaleoni \& Oliveira (2019) destacam que:

Resguardadas as discussões sobre o contexto neoliberal que permeou a promulgação dos PCN, diversos pesquisadores indicam que as pesquisas sobre este documento oficial compreendem um contínuo em que: um dos extremos indica de que OS PCN representam uma possibilidade de repensar práticas educativas e formular políticas públicas sobre diversidade sexual e de género de modo a contemplar as múltiplas realidades que atravessam a escola; e em outro extremo, os PCN são compreendidos como um instrumento que se volta para o controle da saúde pública, dada a apresentação da temática sob vieses majoritariamente biológicos (p. 1541).

A legislação mais atual referente ao currículo escolar, a qual se configura na Base Nacional Comum Curricular em 2018, esteve envolvida por muitas polémicas em relação às questões de sexualidade e género. Na sua aprovação, os termos género e orientação sexual foram suprimidos do documento, em decisão do Conselho Nacional de Educação, acatando as modificações do Ministério da Educação (MEC) (Ferreira \& Mariz, 2017).

Silva, Brancaleoni \& Oliveira (2019) realizaram uma análise documental acerca dos temas diversidade sexual e de género na BNCC, onde tiveram como objetivo "compreender as concepções de sexualidade e género que pautam a BNCC e em que medida esse documento oficial subsidia a prática docente no que se refere a tal temática" (p. 1544).

A partir da análise, os autores destacam que a questão da sexualidade ainda está intimamente ligada às Ciências Naturais, se ausentando a discussão nas demais áreas. Isso destaca o entendimento do conceito de sexualidade apenas na sua dimensão biológica, sem levar em conta questões históricas, sociais e culturais que abarcam esse conceito.

Além disso, os autores destacam que 0 aparecimento da abordagem do tema apenas no 8. .0 ano dos Anos Finais do Ensino Fundamental e a supressão dos temos género e orientação sexual do documento, evidenciam 
o silenciamento e a manutenção de situações de violência e preconceito no meio escolar, como a homofobia, a lesfobia, a misoginia, a transfobia, entre outros.

Nesse sentido, observa-se a conceção de escola que ainda reproduz e mantém as desigualdades sociais, podendo ser assim acentuadas pela exclusão de temas polémicos dos currículos escolares, como as questões de género.

Apesar de existirem unidades temáticas nos Anos Iniciais de Ensino Fundamental em que as discussões sobre questões de género e sexualidade podem ser abordadas, isso, por si só, não garante as discussões. Sem uma política de formação inicial e, principalmente, contínua de professores e pedagogos que garantam a discussão desses temas, combinado com a abordagem emancipatória de forma explícita nos currículos escolares, as questões de género e sexualidade podem ser submetidas ou não a abordagem dos temas, ou serem submetidas apenas à uma abordagem biológica e higienista.

A transversalidade da Educação Sexual é positiva no sentido de mostrar o quanto esse tema está envolvido com outros aspetos que podem ultrapassar as abordagens biológicas e higienistas. Entretanto, a não especificação desse trabalho com objetivos e habilidades a serem desenvolvidas, pode silenciar e abafar a abordagem das questões de género e sexualidade nos Anos Iniciais do Ensino Fundamental. Além disso, também podem gerar abordagens equivocadas pelos professores como 0 aconselhamento e a difusão de informação não-científica para os estudantes.

Já a obrigatoriedade é boa, mas não necessariamente garante a mudança de cultura, por envolver outras questões, como conceções individuais dos próprios professores. Acredita-se que seja necessário a realização de um trabalho de formação e de acompanhamento do trabalho nas escolas. Nesse sentido, observa-se uma sistemática de trabalho em Portugal com a Lei n.ำ 60/2009 que garante a implementação da Educação Sexual de maneira sistemática, com acompanhamento e avaliação desse trabalho. Porém, embora legitime os professores para este trabalho, a lei por si só não se tem revelado suficiente para assegurar a abordagem da ES em todas as escolas portuguesas.

Em relação a formação inicial de professores da educação básica em Portugal, Valente, Branco e Silva (2017) destacam que houve, nos últimos anos, uma integração de unidades curriculares (UC) em Educação para a Sexualidade num número significativo de instituições de ensino onde existem a Licenciatura em Educação Básica. Entretanto, essa questão aparece mais representada nas UC que estão relacionadas à educação para a saúde, com caráter obrigatório. Já as UC específicas sobre Educação para a sexualidade são de caráter opcional.

Já em relação à formação contínua e à educação em nível de mestrado, os autores afirmam que esses não preenchem a lacuna de formação docente em relação à Educação para a sexualidade holística, preconizada pelos documentos em nível nacional, europeu e internacional.

Acredita-se que a formação contínua do professor dos primeiros anos da educação básica é essencial para que algumas características da cultura escolar se modifiquem e a abordagem em Educação para a sexualidade, onde se envolvem as questões de género, se modifiquem. Além disso, acredita-se que a formação inicial e contínua instrumentaliza o professor para que se consolide a legitimação do trabalho sobre temas relacionados às questões de género e à sexualidade.

\section{CONCLUSÃO}

Este artigo teve como objetivo apresentar os resultados iniciais da análise documental das legislações e documentos oficiais em relação ao trabalho sobre Educação para a Sexualidade nos níveis de ensino dos Anos Iniciais do Ensino Fundamental no Brasil e de Primeiro Ciclo da Educação Básica em Portugal.

Percebe-se que a obrigatoriedade da Educação Sexual em Portugal possibilitou um trabalho sistemático e específico no tratamento dos temas sexualidade e questões de género, com acompanhamento e avaliação do trabalho nalgumas escolas. Entretanto, apesar de contemplado na lei e, como tal, legitimado, são diversos os desafios relacionados a esse trabalho, principalmente no que diz respeito a formação contínua dos docentes de educação básica. 


\section{EDUCAÇÃO SEXUAL E LEGITIMIDADE DO PROFESSOR DE ENSINO BÁSICO: UM ESTUDO COMPARATIVO ENTRE BRASIL E PORTUGAL}

Além disso, com 0 atual documento que apresenta um referencial curricular para orientar a Educação para a Sexualidade no país, o qual atende aos objetivos para a abordagem desse tema especificados pela OMS e pela UNESCO, caminha-se para a consolidação do trabalho dos temas relacionados à questão de género e sexualidade com as crianças pequenas, principalmente no 1.․ㅡ.

Já em relação à realidade brasileira os desafios são diferentes. Acredita-se que a exclusão dos termos orientação sexual e género da BNCC, principal documento norteador dos currículos escolares, configura-se como um retrocesso e a negação de direitos fundamentais de grupos historicamente excluídos do processo educacional, como mulheres e pessoas LGBT. Além disso, mantém a ideia de que a escola não é um local de discussão desses temas, limitando 0 acesso à informação e ao conhecimento científico das crianças. Acredita-se também que não explicitar 0 trabalho em Educação Sexual nos Anos Iniciais do Ensino Fundamental fere 0 direito de acesso à informação e construção de conhecimento acerca do tema.

Dessa forma, na continuação desta investigação, espera-se perceber e analisar como o professor de educação básica enxerga o seu papel na abordagem desses temas e se o mesmo se reconhece como um profissional legitimado para realizar a discussão sobre temas relacionados às questões de género e sexualidade em meio escolar.

\section{REFERÊNCIAS BIBLIOGRÁFICAS}

Almeida, F., Ghisi, E., \& Rodrigues, N. (2019, outubro 25) "Sem discutir género, não vamos conseguir prevenir a violência sexual", diz pedagoga. MST. Recuperado de: https://www.mst.org.br/2019/10/25/sem-discutirgenero-nao-vamos-conseguir-prevenir-a-violencia-sexual-diz-pedagoga.html.

Ayer, F., \& Bottrel, F. (2017, março 9). Brasil é país que mais mata travestis e transexuais. Estado de Minas. Recuperado de: http://www.em.com.br/app/noticia/especiais/dandara/2017/03/09/noticia-especialdandara,852965/brasil-e-pais-que-mais-mata-travestis-e-transexuais.shtml

Barifouse, R. (2019, junho 13). STF aprova a criminalização da homofobia. BBC News Brasil São Paulo. Recuperado de: https://www.bbc.com/portuguese/brasil-47206924.

Brasil. Ministério da Educação. (1997). Parâmetros Curriculares Nacionais: orientação sexual. Brasília: MEC/SEF.

Brasil. (2018). Base Nacional Comum: Educação é a base. Brasília: MEC.

Carta Capital. (2019, agosto 30) Damares apoia decisão de retirar estudos de género de escolas de SC. Educação, Carta Capital. Recuperado de: https://www.cartacapital.com.br/educacao/damares-apoia-decisao-de-retirarestudos-de-genero-de-escolas-de-sc/.

Cecílio, C. (2019, outubro 8). O que Geografia tem a ver com Género e Sexualidade? Nova Escola. Recuperado de: https://novaescola.org.br/conteudo/18426/o-que-geografia-tem-a-ver-com-genero-e-sexualidade.

Centro Regional de Informação das Nações Unidas (UNRIC). (2013, junho 20). Relatório da ONU aponta que mais de um terço de todas as Mulheres são afetadas pela Violência Física ou Sexual. UNRIC. Recuperado de: http://www.unric.org/pt/actualidade/31168-relatorio-da-onu-aponta-que-mais-de-um-terco-de-todas-asmulheres-sao-afetadas-pela-violencia-fisica-ou-sexual-.

Cinco dos acusados pela morte da travesti Dandara são condenados. (2018, abril 6). G1 Ceará. Recuperado de: https://g1.globo.com/ce/ceara/noticia/cinco-dos-acusados-pela-morte-da-travesti-dandara-sao-condenados.ghtml

Ferreira, P. \& Mariz, R. (2017, dezembro 12). CNE retira género e orientação sexual da Base Curricular. Sociedade, 0 Globo. Recuperado de: https://oglobo.globo.com/sociedade/educacao/cne-retira-generoorientacao-sexual-da-base-curricular-22179063.

Fonseca, J. P. da. (2019, setembro 6) Ideologia contra educação no governo Doria. Exame. Recuperado de: https://exame.abril.com.br/blog/joel-pinheiro-da-fonseca/ideologia-contra-educacao-no-governo-doria/.

Furlani, J. (2011). Educação Sexual na Sala de Aula: relações de género, orientação sexual e igualdade étnicoracial numa proposta de respeito às diferenças. São Paulo: Autêntica.

Louro, G. L. (2014). Género, sexualidade e educação: uma perspectiva pós-estruturalista. Petrópolis, RJ: Vozes. 


\section{PSICOLOGÍA, INFANCIA Y EDUCACIÓN}

Lusa (2016). Mais de 450 mulheres assassinadas nos últimos 12 anos. Diário de Notícias. Recuperado de: http://www.dn.pt/sociedade/interior/mais-de-450-mulheres-assassinadas-nos-ultimos-12-anos-em-portugal-5516225.html

Moura, R. M. (2019, outubro 29) Itamaraty diz ao STF que tem 'atualizado' posicionamento, inclusive sobre género. Terra. Recuperado de: https://www.terra.com.br/noticias/itamaraty-diz-ao-stf-que-tem-atualizado-posicionamento-inclusive-sobre-genero,c00b2fa2883d93f9a12fc7f3c4effef4ebmvy2hg.html.

Portugal. Assembleia da República. (2009). Estabelece o regime de aplicação da educação sexual em meio escolar. Lei n.․ㅜ 60/2009 de 6 de Agosto. Diário da República, I Série n. 151, pp. 5097-5098.

Portugal. (2017). Referencial de Educação para a Saúde. Lisboa: Ministério da Educação.

Scott, J. (1995). Género: Uma categoria útil de análise histórica. Educação \& Realidade, 20(2), pp. 71-99.

Silva, C. S. F. da, Brancaleoni, A. P. L. \& Oliveira, R. R. de. (2019). Base Nacional Comum Curricular e Diversidade Sexual e de Gênero: (Des)caracterizações. RIAEE, 14(2), pp. 1538-1555.

Simmoneaux, L. (2003). L'argumentation dans les débats en classe sur une technoscience controversée. ASTER № 37, pp. 189-214.

Toledo, L. F. (2019, fevereiro 4). Maioria diz que género e sexualidade devem entrar no currículo escolar, diz pesquisa encomendada pelo MEC. G1. Recuperado de: https://g1.globo.com/educacao/noticia/ 2019/02/05/maioria-diz-que-genero-e-sexualidade-devem-entrar-no-curriculo-escolar-diz-pesquisa-encomendada-pelo-mec.ghtml

UNESCO (2009). International technical guidance on sexuality education: An evidence informed approach for schools, teachers and health educators. Vol. I The rationale for sexual education. Paris: UNESCO.

Unesco. (2016). UNESCO no Brasil se Posiciona sobre Questões de Violência de Género. UNESCO. Recuperado de: http://www.unesco.org/new/pt/brasilia/about-this-office/single-view/news/unesco_in_brazil_stands_ against_gender_violence_issues/\#.V8YOhZgrJNA.

UNESCO (2018). International Technical Guidance on Sexuality Education - an evidence-informed approach (second revised edition). UNESCO, Paris, France.

Valente, B., Branco, D. \& Silva, M. J. (2017). A formação em educação sexual de educadores/as de infância e docentes do $1^{0}$ e $2^{0}$ ciclo do ensino básico em Portugal. Enseñanza de Las Ciencias, nํe extraordinário, pp. 2243-2248.

Vianna, C. P., Carvalho, M. P. de, Schilling, F. I. \& Moreira, M. de F. S. (2011). Género, sexualidade e educação formal no Brasil: uma análise preliminar da produção acadêmica entre 1990 e 2006. Educação \& Sociedade, 32(115), abr. 2011, pp. 525-545.

World Health Organization (WHO). (2006). Defining sexual health. Geneva: World Health Organization.

World Health Organization (WHO) \& Regional Office for Europe and BZgA. (2010). Standards for Sexuality Education in Europe: a framework for policy makers, educational and health authorities and specialists. Cologne: Federal Center for Health Education, BzgA. 
